\title{
LA CIENCIA IRRUMPE EN LA ÉTICA MÉDICA: NEUROÉTICA Y PSICOANÁLISIS DE FREUD
}

\author{
Gustavo Figueroa Cave ${ }^{1}$
}

Resumen: El psicoanálisis y la neuroética se ocupan de los fenómenos éticos que nacen de la aplicación de técnicas y tecnologías surgidos de las ciencias de la psiquis. Existe una considerable coincidencia entre los tópicos cubiertos por la neuroética y los fenómenos conceptuales que han constituido la ocupación de los psicoanalistas. La neuroética descansa en una perspectiva biologicista, en la que es real solo aquello que es biológico; con ello entrega una visión de la ética que limita el significado del único tema que importa al psicoanálisis: la comprensión de los significados inconscientes y el papel del discurso para discernir y justificar estos sentidos. La neuroética ha conducido a la ética a considerar lo sensorial, lo físico y lo visual, a expensas del significado psicológico de la dimensión psíquica de la existencia humana.

Palabras clave: neuroética, el psicoanálisis, significado inconsciente, sin querer, productos biológicos

The irruption of science in medical ethics: neuroethics and Freud's psychoanalysis

Abstract: Psychoanalysis and neuroethics are concerned with ethical issues arising in the application of techniques and technologies stemming from the sciences of the mind. There is considerable overlap between the topics covered in neuroethics and in conceptual issues with which psychoanalists have long been concerned. Relying on a biologistic perspective, whereby only what is biological is real, neuroehtics offers a vision of ethics that limits the significance of the unique psychoanalytic concern: the understanding of unconscious meanings and the role of discourse in discerning and justifying these meanings. Neurethics has been leading ethics toward an appreciation of the sensory, the physical, the visual, at the expense of psychological meaning, the psychic dimension of human existence.

Key words: neuroethics, psychoanalysis, unconscious meaning, free willing, biologicism

A ciência irrompe na ética médica: neuroética e psicanálise de Freud

Resumo: A psicanálise e a neuroética se ocupam dos fenômenos éticos que nascem da aplicação de técnicas e tecnologias surgidos das ciências da psiquê. Existe uma considerável coincidência entre os tópicos cobertos pela neuroética e os fenômenos conceituais que tem constituido a ocupação dos psicanalistas. A neuroética descansa numa perspectiva biologicista, na qual é real só aquilo que é biológico; com isso entrega uma visão da ética que limita o significado do único tema que importa à psicanálise: a compreensão dos significados inconscientes e o papel do discurso para discernir e justificar estes sentidos. A neuroética tem conduzido a ética a considerar o sensorial, o físico e o visual, às expensas do significado psicológico da dimensão psíquica da existência humana.

Palavras-chave: neuroética, a psicanálise, significado inconsciente, sem querer, produtos biológicos

\footnotetext{
${ }^{1}$ Departamento de Psiquiatría, Escuela de Medicina, Universidad de Valparaíso, Chile Correspondencia: gfigueroacave@gmail.com
} 
El impresionante avance de las neurociencias ha traspasado los límites de laboratorios y biotecnologías aplicadas, configurando de un modo revolucionario la realidad del siglo XXI: es la neurocultura, que se expresa en el arte, la ciencia, la religión, la política. Nacieron independiente, aunque conceptualmente relacionadas, la neuroestética, neuroteología, neurofilosofía, neuroderecho, neurosociología, neuroeconomía, neuroeducación, neuroética. La neuroética surgió en 2002 como "el estudio de las cuestiones éticas, legales y sociales que surgen cuando los descubrimientos científicos acerca del cerebro se llevan a la práctica médica, las interpretacione legales y las políticas sanitarias y sociales", según palabras de William Safire(1). Emparentada con la bioética ecológica de Potter y médica de Hellegers y Callahan, rápidamente trascendió sus metas y se dividió en dos. Por una parte, como Ética de las Neurociencias regula, ordena, guía y sanciona el comportamiento en la investigación neurocientífica y su aplicación en los seres humanos; por otra, como Neurociencia de la Ética pretende resolver cuál es la esencia y cómo se genera la moralidad como tal. Esto es, neuroética aplicada y neuroética fundamental(2-6). Así, hoy, la ciencia empírica se enfrenta a toda la tradición de la filosofía occidental para resolver el enigma inherente al hombre: su condición de ser ético. No es la primera vez, pero ahora se lleva a cabo con preguntas específicas, procedimientos estandarizados y validaciones objetivas.

A comienzos del siglo XX Freud también lo intentó, valiéndose de la ciencia psicoanalítica. En la carta del 31 de mayo de 1897 , dirigida a su amigo Fließ, le comunica su intuición fundamental: "Otro presentimiento me dice, como si ya lo supiera - aunque en verdad yo no sé nada en absoluto- que estoy por descubrir la fuente de la moralidad" (7). La intuición fue fulgurante y la fue desarrollando meticulosamente hasta el final de sus días con dos características propias: nueva manera de interrogar y diferente perspectiva para interpretar las respuestas consagradas sobre la ética. Se puede hablar, aunque con bastante precaución, de una Ética del Psicoanálisis y un Psicoanálisis de la Ética.

Sin embargo, hacia finales del siglo XIX Nietzsche había decretado "la muerte de Dios": el derrumbe de todo el mundo de los ideales, especialmente de los valores, incluidas las verdades que sustentaban la cultura occidental. "No existen hechos morales (...), la moral es únicamente una interpretación de ciertos fenómenos..., (pero) una interpretación equivocada (Mibdeutung)"(8). Surge el fantasma del nihilismo, de un mundo gélido porque "no hay nada fuera del todo ¡Que no se haga ya responsable a nadie! El ámbito entero de la moral cae bajo este concepto de las causas imaginarias". Este nihilismo amenazador significa la pérdida de la vigencia de los valores hasta entonces considerados inconmovibles y la ausencia de sentido de la existencia. Por ello hablamos hoy día de una sociedad axiológicamente politeista — "hay más ídolos que realidades", en palabras de Nietzsche-, desorientada en sus finalidades, sin bienes internos, carente de fundamentos, una sociedad técnica y económicamente deslumbrante, pero "después" de la virtudes; por lo que es indispensable, según MacIntyre, "ir tras” ellas (after virtue) (9). Pero Vattimo sostiene, contrariamente, que "la filosofía no puede ni debe enseñar a dónde nos dirigimos, sino vivir en la condición de quien no se dirige a ninguna parte" (10).

Las ciencias empíricas trabajan al interior, aunque resueltamente en contra, de este nihilismo corrosivo, planteando hipótesis creativas, proponiendo modelos y entregando respuestas que aspiran a la objetividad en ética. El presente trabajo tiene una doble tarea en esta ambición de entender lo moral del ser humano (enfermo). Por una parte, comprender las similitudes que subyacen a ambas aproximaciones científicas y, por otra, diferenciar sus puntos de vista, aunque acentuando que una y otra ocupan un lugar determinante en la ética médica actual.

\section{La ciencia enfrenta el fenómeno moral}

Tanto el psicoanálisis como la neuroética aspiran a ser ciencia en el sentido moderno de la palabra: formular hipótesis, elaborar experimentos rigurosos, entregar datos empíricamente contrastables(11). Pero ya ha quedado claro que la ciencia no es un "espejo de la naturaleza" y que la razón científica no refleja fielmente los sucesos del mundo sino que los interpreta y aun construye(12). "Ya no se toman todos los datos por buenos dice Bunge-: corregimos la experiencia, adop- 
tando promedios o medianas y eliminando los datos que parecen irrazonables (...), estamos más intolerantes o exigentes con los datos empíricos, pero más tolerantes para con las teorías"(13).

Esto significa que tanto Freud como la neuroética se conforman en su estudio de la moralidad acatando los principios válidos para el ámbito neurobiológico elaborados por Kandell y que encontraron gran aceptación en psiquiatría y psicología. Los principios, al aplicarlos a la ética, son los siguientes: I) "Todos los procesos mentales, aun los procesos psicológicos más complejos (morales), derivan de operaciones del cerebro"; (II) "Los genes y los productos de sus proteínas son determinantes importantes del patrón de interconexiones entre las neuronas en el cerebro y los detalles de su funcionamiento"; (III) "Los genes alterados no explican, por sí mismos, toda la varianza de un (trastorno ético) grave dado"; (IV) "Las alteraciones inducidas en la expresión génica por el aprendizaje dan lugar a cambios en los patrones de las conexiones neuronales"; y (V) "En la medida en que la psicoterapia o la consejería son efectivas y producen cambios de largo plazo en la conducta (moral), se presupone que lo hacen a través del aprendizaje, produciendo cambios en la expresión génica que altera la fuerza de las conexiones sinápticas y cambios estructurales que alteran el patrón anatómico de interconexiones entre las células nerviosas del cerebro"(14).

Kendler fue más atrás aún y esbozó los fundamentos conceptuales a la base de las ciencias neurobiológicas: I) "El dualismo cartesiano de las sustancias es falso"; 2) "El epifenomenalismo es falso"; 3) "La causalidad cerebro mente y mente cerebro son igualmente verdaderas"; 4) "Las (modificaciones morales) son etiológicamente complejas"; 5) "El pluralismo explicatorio es preferible al monismo explicatorio, especialmente al reduccionismo biologicista"; 6) "(La moralidad) necesita moverse desde una "batalla de paradigmas" precientífica hacia un acercamiento más maduro que comprenda la complejidad junto con modelos empíricamente rigurosos y pluralísticamente explicatorios", y 7) "Debemos aceptar un «reduccionismo por parches» con la finalidad de la integración por segmentos cuando se trata de explicar las vías etiológicamente complejas hacia las (conductas morales)" (15).
He aquí las áreas principales que comparten la neuroética y el psicoanálisis como ciencias del estudio de la moralidad del ser humano:

1) Procesos mentales inconscientes. Los experimentos de Libet, confirmados por Haggar y Eimer, determinaron que la vida moral se despliega en zonas inadvertidas por el sujeto, de modo que las deliberaciones, elecciones y decisiones que lleva a cabo en su vida cotidiana son efectuadas sin que él mismo participe de modo reflexivo(16-19). Midiendo los potenciales cerebrales de la corteza mientras se ejecutan movimientos voluntarios, se determinó que estos se adelantan en 350 milisegundos a las decisiones conscientes para ejecutar estos movimientos, lo que permite suponer que son mecanismos extraconscientes -neuronales - los que ocasionan efectivamente las acciones supuestamente volitivas y que estas, retrospectivamente, son erróneamente catalogados como propias. Por su parte, los pacientes de Freud le mostraron la existencia de sentimientos de culpa inconscientes que decidían su comportamiento y eran producto de pensamientos, deseos y actos contrarios a sus estándares morales conscientes, como por ejemplo en el duelo y la melancolía(20); en otras palabras, lo éticamente reprobable - la falta - era totalmente desconocida, ignorada, aunque fuera la causante del autocastigo, pero sin ser reconocida ni menos asumida como propia.

2) Libertad y determinismo. Desde sus comienzos, Freud postuló el determinismo psíquico: el supuesto destino (externo, de los dioses) de Edipo de matar a su padre Layo respondía en verdad a deseos (íntimos), incorporados en su pasado más remoto, de asesinarlo para poseer a su madre (21); los actos así llamados casuales, como el olvidar nombres o equivocarse al escribir, están condicionados desde la más recóndita zona de la psiquis porque repelen a nuestra consciencia ética(22); por tanto, no "somos dueños ni de nuestra propia casa" (23), nuestra ética obedece a procesos que están ubicados en la cadena causal de la psiquis arcaica inconsciente. A su vez, la neuroética seńala que la voluntad no es libre para escoger sus acciones (entenderse por motivos, saberse agente y autor, y creerse con poder para conducirse distintamente en situaciones semejantes externamente), porque, como se señaló, la elección es 
una ilusión que se proyecta con posterioridad al pasado después de que el cerebro ha fijado previamente el curso a seguir: "la función del cerebro es tomar decisiones" (24).

3) Responsabilidad. Los experimentos neuroéticos proponen que, si es el cerebro el que toma decisiones, la responsabilidad del sujeto se termina; en otros términos, las acciones que requieren de la intencionalidad consciente se convierten en movimientos. Si las razones ya no participan en los actos porque son simples movimientos, entonces los fundamentos para adscribirles racionalidad están errados, vale decir, no hay responsabilidad porque, como decía Ryle, no existe un fantasma en la máquina $(25,26)$. Para Freud, la responsabilidad es un asunto complejo y, al planteársele con motivo de un grupo de transgresores, la resolvió acudiendo al concepto del criminal por sentimientos de culpa: los actos delictivos se ejecutan como medio de pagar emocionalmente lo que en otro ámbito - e inconscientemente- han llevado a cabo, como el matar (simbólicamente) al hermano para conseguir (el cariño exclusivo de) la madre(27).

4) Las emociones. Si para la neuroética las razones que damos para justificar nuestras elecciones no son sino ilusiones retrospectivas, significa que los juicios morales no obedecen a la razón sino a la emoción, a la intuición. Las normas morales nos dicen lo que no se debe hacer, pero cuando llevamos a cabo un acto prohibido, este nos hace sentir de inmediato el afecto de lo indebido o reprobable, pero no entrega razones valederas inmediatas que justifiquen el sentimiento ante este accionar, sino que retrospectivamente racionaliza con motivos; esta autopercepción lleva a un "desconcierto moral" porque somos, en palabras de Haidt basadas en sus experimentos, un perro emocional con una cola racional(28). Contrariamente a lo postulado por Kant, "la razón (no) determina completamente a la voluntad"(29). Por su lado, Freud habla de las pulsiones (Trieb), pero esta es una hipótesis biológica que se expresa en la clínica médica en emociones, en el deseo. Es el deseo el objeto directo de análisis de Freud, pero no es el deseo o emoción aislado sino el deseo captado en referencia con un mundo, especialmente el ambiente primero de apego a los padres como figuras de autoridad, con la moral o censura proveniente del superyo (inconsciente) de los padres que se formula en prohibiciones que luego anidan en su propio superyo por introyección del de sus progenitores(30).

5) Identidad. La neuroética postula que somos nuestro cerebro - "la conducta de una vasta asamblea de células nerviosas y de las moléculas a ellas asociadas", según Crick(31)—y que es el cerebro el ético(32). Si el cerebro es el propiamente moral significa que él está a cargo y manda, él es el que decide nuestras opciones y preferencias valóricas(33). Nuestra identidad como persona nos la da el cerebro, porque "nuestros cerebros definen quienes somos mejor que nuestros genes, investigando el cerebro investigamos el yo"(34). Ahora bien, si el cerebro es el centro esencial de nuestra vida, no se puede confundir con la mente o con la persona, porque es el asiento de la mente pero no se identifica con nuestra mente o persona. Lo cual implica que se pierde la identidad como se la entiende corrientemente, hay múltiples identidades según sea la zona exitada por las neuronas, neuronas que funcionan coordinada, alternativa y secuencialmente, siguiendo los principios de una red interconectada. De manera demasiado concreta Dennet lo ejemplifica diciendo que "si uno ingresa al cerebro por el ojo, camina hasta el nervio óptico, dando vueltas y vueltas alrededor del córtex, buscando detrás de cada neurona y luego, antes de percatarse de ello, emerge a la luz del día montado sobre un impulso nervioso, rascándose la cabeza y preguntándose dónde está el yo"(35). En Freud, fueron sus pacientes quienes le mostraron desde sus inicios que la escisión de la persona no es una anomalía, sino el modo como la psiquis está constituida(36), y su posterior tópica, yo, ello, superyo, no vino sino a ratificar esta concepción primera, siendo el superyo el encargado de entregar su identidad ética, aunque incluso esta identidad ética también está desmembrada(37). Freud reconoció que hay que desistir de la necesidad de unificación, de conseguir una versión oficial y congruente de la propia infancia, del carácter, de la moral(38). Es necesario hablar de un yo descentrado y compuesto de varios interlocutores válidos (ego, ello, superyo); no se puede exigir una historia coherente y unificada, sino conformarse con un agregado de narrativas alternativas y plausibles; hay que perder la identi- 
dad permanente, para ganar un sí mismo partido en grupos de creencias alternantes y autónomos; la ética no se somete a un soberano, juez o dueño de principios y virtudes, sino a un sujeto que no es amo de sí y no es predecible en sus objetivos y propósitos(39). Edipo al comienzo de la tragedia, buscador inmisericorde e impoluto, poseedor de la ley, no es el Edipo culpable del final, que necesita arrancarse los ojos como expiación de sus culpas ignominiosas ignoradas anteriormente, pero arraigadas en su infancia perdida, y que lo obligaron a exiliarse, de sí y de los otros(40).

\section{La neuroética frente al psicoanálisis de Freud}

Hasta aquí se han visto las principales áreas comunes entre la neuroética y el psicoanálisis de Freud. Pero zonas compartidas no significa, ni mucho menos, acuerdos, ni siquiera parentescos. Existen enormes diferencias, siendo la primera su estatuto como ciencias. Ambas pretenden serlo, aunque de distinta manera. La neuroética se declara ciencia natural y procede apoyándose en los resultados de las actuales neurociencias; acude preferentemente, aunque no exclusivamente, al diseño experimental(41). En el caso de Freud, más allá de sus intenciones explícitas de hacer ciencia(42), ha sido cuestionado desde sus inicios, aun con ferocidad(43). Se ha negado al psicoanálisis su carácter de ciencia empírica, porque no cumple con sus criterios, especialmente la contrastabilidad con datos objetivos(44-50). Otras veces se le ha juzgado como un conjunto de hipótesis que se encuentra en la etapa de preciencia(51); o como una suerte de Weltanschauung(52), quizás estimulante como pensamiento que reflexiona sobre la condición del ser humano a partir de un vasto y exhaustivo conocimiento de la cultura clásica y moderna, pero carente de los fundamentos, métodos y metas propios de la ciencia actual $(53,54)$. Ricoeur opta por otro camino: le asigna un lugar especial y único porque, no siendo ciencia de tipo observacional ni natural, postula el de ciencia hermeneútica, con sus criterios particulares, pero definidos, de qué constituye un "dato" comprobable y cómo se obtiene la verificación partiendo de la situación analítica; lo hermenéutico significa que Freud actúa en un doble nivel, porque se ocupa de lo simbólico del hombre y, por tanto, del doble sentido: el nivel de lo literal o inmediato e, interpretando ese nivel, pasa al de lo encubierto; "la interpretación es la inteligencia del doble sentido" (55-58).

Los puntos de vista discrepantes se enumeran someramente a continuación.

1) La Ética de las Neurociencias ha estado especialmente resuelta a precisar los alcances morales de las ciencias neurobiológicas cuando se aplican al ser humano y ha elaborado una serie de mediciones cuantitativas, pruebas instrumentales y guías objetivas, con el fin de guiar, prevenir, castigar y teorizar. En otras palabras, está cuantificando el poder de la ciencia en el ámbito ético. Ha incursionado en múltiples áreas a gran velocidad, porque no ha propuesto límites ni restricciones morales sustantivos a sus investigaciones, siendo estas algunas de las que se enumeran a continación. Así se ha interesado por estimar el impacto de las vivencias en la intimidad cuando son traumáticas o cuando se pretende la implantación de otras distintas para transformar la historia personal. ¿Es lícita la producción de un cambio de ideología en el sujeto con el fin de alterar su autovalía o trastocar su identidad personal al borrarle acontecimientos infantiles penosos o violentos? La utilización de procedimientos imaginológicos para comprobar la presencia de engaños, falsificaciones, mentiras intencionales en juicios o en litigantes que pretenden conseguir ventajas directas o indirectas internas emocionales, ¿qué validez moral tiene? La creación de "huellas cerebrales" por medio de neuroimágenes o del "test de conocimiento culpable" en ondas cerebrales para fijar la imputabilidad de actos cometidos por sujetos en la vida cotidiana, ¿hasta qué límite es tolerable? La medición instrumental objetiva de las capacidades para entregar consentimiento informado permite compararlas con tablas estadísticamente estandarizadas y así da a conocer si un individuo no puede superar la barrera inferior mínima, que está inhabilitado para elegir racionalmente opciones que le conciernen; sin embargo, ¿se justifica aceptar una tabla como estándar? ¿O trasladar la respuesta a lo que había expresado durante su vida consciente? ¿O a sus herederos? ¿O a la autoridad judicial? Las técnicas de neuroimágenes están permitiendo predecir enfermedades futuras: ¿se las debe comunicar al paciente, a pesar de la ausencia de certeza absoluta? ¿A sus hijos? ¿A su futura esposa? ¿A las aseguradoras? ¿A los votantes, si es 
un candidato? A personas con trastornos severos de la personalidad y que los conduce a actos delictivos o asesinos, ¿se les puede extirpar partes del cerebro? ¿Está permitido insertarles chips para controlar sus neuronas? Las nuevas drogas están logrando mejorar ciertas capacidades durante determinados momentos ¿qué consecuencias éticas están avalándolas? ¿No está la intención de obtener rendimientos sobrehumanos? Detrás de los experimentos en células troncales para evitar enfermedades, ¿se esconde la mejoría de la raza humana, como introducir núcleos de ciertas donantes en óvulos de receptores y fabricar personas a la medida en cuanto a inteligencia, capacidad física, belleza, y desechar lo considerado inservible para estos fines?(59).

La Neurociencia de la Ética investiga las bases biológicas de la ética para proponer una moral universal común a la especie humana. Producto de estudios obtenidos de otras ciencias - arqueología, etnología, evolucionarismo-, Wilson recordó que el hombre del pleistoceno era cazadorrecolector, vivía en comunidades limitadas a 130 individuos de raza, costumbre y religión homogéneas. El vínculo social estrecho, constante y seguro les permitió sobrevivir y superar con éxito las múltiples amenazas de un ambiente peligroso y amenazante. La dependencia de la ayuda mutua, las labores compartidas, el socorro que se prestaban entre sí era una condición biológica básica e ineludible, y esta condición material es la que hizo posible el nacimiento de la moral primaria. Por tanto, la moral es una función biológica de supervivencia como otras funciones y, por medio de un proceso de selección natural, los afectos, emociones e instintos que favorecen la ayuda mutua con los cercanos e inmediatos, y excluyen, expulsan o eliminan a los extrańos y desconocidos son trasmitidos a los descendientes(60). Así, el cerebro grabó en sus circuitos neuronales estos códigos de funcionamiento moral con el correr de millones de años y estos códigos, por estar impresos en las neuronas, sinapsis y circuitos son universales, válidos para toda la raza humana. Son una especie de gramática universal ética producto de la selección. Aquellas normas de proceder moral que actuaban de modo muy rápido, sin la mediación de procesos racionales y cognitivos superiores, fueron seleccionadas porque estos últi- mos retardan su eficacia y facilitan el exterminio del individuo y tribu $(61,62)$. En el fondo es una moralidad basada en la reciprocidad, ya sea fuerte o débil. Hasta hoy se plantea que, si las hipótesis de su nacimiento son valederas, esta moralidad biológicamente condicionada se regiría siguiendo un imperativo categórico muy diferente al planteado por Kant - reconoce en todo ser humano un fin en sí mismo-(63), que ha sido el código de la modernidad, de occidente y ahora de los derechos humanos. Aunque todavía no se lo explicita abierta y sistemáticamente por sus defensores, debería formularse: "Amarás al cercano y rechazarás al lejano". Una variedad del anterior imperativo, si tomara en cuenta la mencionada reciprocidad, valdría para el altruismo, piedra de tope de todo evolucionarismo, porque cuesta justificarlo en la teoría; para ello se ha recurrido al concepto de altruismo genético o gen egoísta(64, 65), que en ocasiones es indispensable a la hora de alcanzar la supervivencia, porque de lo que se trata en una situación extrema es de proteger a los genes: "Obra con los demás en la medida en que compartan tus genes".

2) Freud parte desde otra perspectiva radicalmente diferente. Su mencionada carta del 31 de mayo de 1897, en la que afirma: "estoy por descubrir la fuente de la moralidad"(7), es producto de sus reflexiones sobre el tratamiento con pacientes, la comprensión de sus sueños durante su autoanálisis y del penetrante intercambio científico personal con su amigo Flieb. Días después le confiesa a este que "en verdad, yo no puedo trabajar sin un público". Esto supone que, a diferencia del laboratorio o condiciones experimentales de las ciencias naturales — programadas, estandarizadas y predeterminadas-, el psicoanálisis de Freud parte de una situación espontánea, directa, la situación analítica (si entendemos su autoanálisis y las revelaciones a Flieb como homólogos de la situación analítica). Y es esta situación la que precisa ser interpretada (Deutung), interpretación que sigue una técnica altamente reglada.

En la experiencia analítica Freud vivenció en profundidad el fenómeno ético del ser humano, específicamente al interior de la relación de transferencia -experiencia única, singular, intransferible(66). La experiencia es esencialmente de carácter lingüístico, incluyendo lo no-verbal; 
el lenguaje por el cual se comunica con sus pacientes tiene significado y poseer sentido es su sello distintivo, el rasgo que aleja a Freud de sus propias formulaciones teóricas positivistas, naturalistas y materialistas (pulsión, Trieb), y de las de las ciencias empiricas de su tiempo, aunque también, de las actuales. Así, cuando Freud analiza los actos de sus enfermos trata con acciones y no movimientos: del sentido del comportamiento y no de la neurofisiología de este, de intenciones de las acciones y no de resultantes motoras consecuencia de exitaciones del ambiente, de propósitos y no de estímulos físiológicos, de agentes y no de portadores, de una "gramática" con su sintaxis especial, diferente a la "gramática" de los cuerpos físiológicos(67).

El hablar en el diván, además de tener un significado, es dirigido a otro, aun cuando se diga que, en ocasiones, es la propia conciencia la que nos ha castigado: la voz de la conciencia es de un otro que, desde el interior, nos dirige la palabra de reproche(68). El habla que estudia Freud es el que proviene de las capas más primarias del ser humano, esto es, del deseo y no de la razón: es el deseo como motivo para actuar el que se expresa a través de un sentido en el medio, en la sociedad, en el mundo de la cultura. Sin embargo, este deseo o afecto se muestra y da a conocer en mayor o menor medida indirectamente, pero siempre conflictivamente con la cultura. Mejor dicho, el mundo cultural — representado por los padres, autoridades, reglas anónimas sociales, instituciones, el analista- se opone, explícita o implicitamente, a las demandas, exigencias o ansias inherentes al deseo que moviliza a sus pacientes.

El deseo impele a descargarse de modo imperioso pero, como está impedido o repudiado por las prohibiciones de los progenitores —el padre-, normas de la sociedad, reglas del análisis, lo efectúa a través de distorsiones, desfiguraciones, desplazamientos, que no son accidentales sino sistemáticas, porque constituyen subsistemas organizados en sectores del inconsciente para hacer posible que este deseo se comunique y se haga patente al terapeuta. Pero la desfiguración, que consigue en engañar a las censuras del padre y del psicoanalista, burla también al sujeto mismo, resulta incomprensible al propio yo.
La transferencia que se despliega en la terapia, a pesar de ser auténtica $(e c h t)$, no se refiere al "mundo real" (wirklich) sino al "mundo interno". Freud lo señala directamente: "Las fantasías (que comunica al terapeuta) poseen realidad psíquica, por oposición a una realidad material..., en el mundo (de los pacientes) la realidad psíquica es la verdadera" (69). Estas fantasías inconscientes presentan una estructura altamente sistematizada y están inscritas en escenarios que son típicos, pero reducidos a unos pocos. De ahí la importancia de las escenas infantiles, escenarios arcaicos que no siempre son "verdaderos", aunque invariablemente están activos en el individuo adulto como recuerdos, aunque "recuerdos encubridores": escenas muy vívidas que tienen que ser interpretadas para captar su significado inconsciente oculto. Así, resulta comprensible que para Freud no son decisivos los hechos observables, ni las conductas perceptivas relacionadas con los acontecimientos del entorno, sino la significación (oculta) que el individuo da a ese grupo de fenómenos. Sin embargo, las fantasías, recuerdos y acontecimientos deben entrar en una historia, en un relato, porque la experiencia analítica posee un carácter narrativo, porque la vida de los pacientes es histórica. Cuando se recuerda algo, lo determinante no es la evocación de ciertos acontecimientos aislados, sino que ese algo forma parte de secuencias significativas, de conexiones ordenadas temporalmente, de tramas con personajes que se despliegan en el presente desde un pasado hacia un futuro.

Hasta aquí los elementos distintivos de la ética de Freud: se estudia a partir de una situación que no es un artificio técnico, cual es la experiencia analítica; su esencia consiste en poseer un sentido; es relacional, puesto que no se encierra en sí sino tiende hacia el otro; proviene de las capas más arcaicas del sujeto, cual es la del deseo o afectividad; no se muestra directamente sino debe ser interpretada, ya que el deseo se exhibe en fantasías primitivas, recuerdos encubridores o actos sintomáticos - acceden a la conciencia por medio de distorsiones y desfiguraciones. La ética está basada en el conflicto - no hay ética sin conflicto, esta es conflictiva por naturaleza-, puesto que el deseo ingresa, se proyecta, a la sociedad, a la cultura que opone barreras, prohibiciones, censuras a través de autoridades, instituciones, 
padres. Además es narrativa, esto es, articulada en historias, en tramas con personajes y argumentos, lo que conduce a una nueva característica: en la moral de Freud, a diferencia de la de Kant, que es a priori u originaria, se trata siempre de una moral a posteriori, constituida, sedimentada. Vale decir, se ha generado, es producto de la historia personal de identificaciones e introyecciones con personas o referentes importantes en el curso de la propia existencia; por tanto, siempre tiene algo de extraña, de enajenada y así de enajenante para el sujeto mismo. El superyo - lugar de la moralidad adulta-, es un "país extranjero interior" (inneres Ausland), el yo frente a este superyo se encuentra oprimido por él. ¿Cómo podría ser de otro modo si es el padre (o sustituto) internalizado?(70).

Pero lo ético no es solo rigor y crueldad frente a lo no acatado y condenado; también es conciencia de sí, mirada a sí mismo, autobservación, ojo interior que escruta, desdoblamiento que se descubre en su propio accionar; pero asimismo es ideal del yo con el que se mide, al que aspira alcanzar y cuya exigencia de una perfección se empeña en cumplir. Así Freud pudo estudiar lo ético partiendo de la clínica del superyo: observación de sí, conciencia moral y función de ideal; vale decir, delirio de observación, melancolía y narcisismo propio del sadismo y masoquismo. Planteó "la patología del deber" — como antes Kant habló de "la patología del deseo"- como corolario de la estrecha conexión entre el afecto y lo sublime, entre el deseo y la culpa, entre el ello y el superyo(39).

Se mencionó que la ética es el precipitado final de una génesis - no es inherente originalmente- y esta génesis es doble. Por un lado, es producto de un drama individual, personal, íntimo: inmersión y resolución del complejo de Edipo, mejor dicho, es el heredero del complejo y, como tal, constituye un secreto interno: los deseos de matar al padre y poseer a la madre se transforman en la introyección de aquel y de su superyo. Por otro, es un destino universal, no arbitrario, que se expone no solo en las distintas producciones artísticas humanas (Hamlet, Edipo), sino en la etnología: la adoración ambivalente del totem por los hombres primitivos no es sino el complejo de Edipo de la especie humana(71). Para Freud —más allá de las insuficiencias metodológicas e históricas que pue- da tener su teoría del totem y del tabú(72,73)—, la analogía entre la historia del individuo y la historia de la especie parece reafirmada indirecta y oblicuamente por la clínica, puesto que en esta existen afinidades, que son estructurales, entre la neurosis obsesiva y el tabú: "un obrar prohibido para el que hay intensa inclinación en lo inconsciente", esto es, el fenómeno de la ambivalencia, que es un rasgo distintivo de la conciencia moral. Pero la postulada historia de la humanidad revela otra dimensión que no da el Edipo personal. La prohibición de matar al padre, el parricidio, proviene del tabú del totem, es individual; pero la prohibición del incesto proviene del fratricidio, de no asesinar al hermano y, con esta última prohibición, que implica una renuncia a la violencia en general, se va más allá de lo individual de la ética, se entra en el nacimiento de la institución de la moral, nace el derecho. La prohibición de matar al padre, parricidio, es individual; la prohibición de matar al hermano, fratricidio, es social.

Al llegar a este punto es necesario recordar que el psicoanálisis es un tratamiento, una terapia que no consiste en el conocimiento intelectual del paciente de aquello que desconoce, ni rectificarlo en lo que conoce falsamente de sí, ni señalarle sobre cómo debe comportarse en su vida cotidiana, ni instruirle cómo afrontar los estrés de la existencia, ni recordarle lo que le sucedió en la infancia, ni enseńarle lo que es socialmente aceptable para conseguir su adaptación. El psicoanálisis es un trabajo (Arbeit), es una labor que se enfrenta a las fuerzas que se oponen al acceso a la conciencia de los deseos reprimidos, es una operación repetida (Durcharbeiten) actuando sobre cantidades de energía pertenecientes a las defensas para su lenta resolución, es una lucha que se experimenta al calor de la transferencia combatiendo las resistencias(74). Por decirlo así, es un lidiar con energías, dinamismos y mecanismos que participan en lo que se podría llamar una economía (simbólica) al interior del deseo.

El resultado final es preciso: la ética de Freud no es una ética de la dominación —una técnica de poder-, sino una ética de la veracidad, una técnica del reconocimiento de sí. Para Freud, el paciente parte del desconocimiento o falso conocimiento de sí (Mibverständnis) y se enfila progresivamente, a través de un sendero lleno de dificultades, fuer- 
zas ocultas y caminos espurios, al reconocimiento de sí mismo. Fue la ruta de Edipo: el destino suyo era ya haber matado a su padre y desposado a su madre —en el comienzo del drama-, pero su historia personal se inicia más allá, reconocerse en el hombre que al comienzo había maldecido y renegado, y, después de su aterradora visión interior, poder decirse "ahora sé quién soy" (40). La técnica psicoanalítica lo permite porque su primera regla al empezar el análisis consiste en decir toda la verdad por dolorosa o absurda que parezca, dejar todo juicio moral afuera con una finalidad específica; el propósito de esta regla es decisiva: la moral no ha de transformarse en criterio de la verdad del sujeto. O sea, provocar una suspensión de la ética corriente para permitir que la ética propia vaya surgiendo desde la intimidad. Pero al término de la terapia no se encuentra al hombre "verdadero" que permanecía atrapado, no hay algo así como una "esencia" que finalmente se alcanza, no existe por detrás del ser "falso" un ser "auténtico". Por eso el psicoanálisis es análisis y no síntesis, no lleva a cabo una labor de esculpir para forjar al final el "yo propio profundo"; su término, si pueda hablarse de tal, es dejar ser al sujeto de modo que este sea lo que él va siendo(39,75,76). El llegar a "lo último" es una nueva ilusión, no aceptar "las durezas de la vida" (Schwere des Daseins). El psicoanálisis no es una ciencia de la predicación, no da soluciones sino comprensiones más amplias y más articuladas, no hay moralismo, ni Freud es un profeta, sino alguien que recuerda lo difícil que es ser hombre porque su existencia es trágica en el sentido de los poetas griegos(23).

\section{La ciencia ante la bioética}

1) Heidegger ha caracterizado a la edad moderna por cinco fenómenos: poseer ciencia moderna, manipular técnica mecanizada, introducir el arte en el horizonte de la estética, interpretar el obrar humano como cultura y haber entrado en la desdivinización o pérdida de los dioses(77). Las neurociencias y biotecnologías actuales son ciencia moderna y esto ha significado que las ciencias han irrumpido, con modos de pensar inéditos, a una dimensión básica que estaba limitada a la filosofía y teología: lo ético inherente al hombre. El psicoanálisis en el siglo pasado ya se había ocupado de la moral, pero ahora en el actual, junto a la neuroética, ha entregado no solo respuestas creativas y novedosas, sino una manera diferente de entender la ética. Pero ambas ciencias comprenden de modo distinto qué es ciencia, cómo se accede a los hechos, cómo se verifica la verdad de sus hallazgos y qué valor de predicción tienen sus asertos, lo que significa que la manera de aprehender y de entregar sus resultados sobre la moral son radicalmente diversos. Esto significa tener un cuidado especial cuando se utilizan expresiones similares, como por ejemplo inconsciente: lo "natural" no puede trasladarse sin más a lo "simbólico", el lenguaje de las expresiones directas propio del proceso secundario es distinto al lenguaje que da a conocer lo disimulado en expresiones codificadas de acuerdo al proceso primario(78). Mientras la neuroética ha intentado resolverlos acudiendo especialmente al método experimental, situaciones controladas y la medición cuantitativa, el psicoanálisis se ha servido de métodos cualitativos, la situación analítica espontánea y la búsqueda de sentido.

2) Al ocuparse de la moral aplicando el método científico el psicoanálisis y la neuroética han enfrentado y entregado respuestas a problemas substanciales del ser humano, que han sido determinantes del pensamiento de occidente desde la Grecia clásica: dicotomía determinismo-libertad, naturaleza de la moral, posibilidad de una ética universal, identidad del yo, relación mente-cuerpo, esencia del hombre.

3) La neuroética habla de cerebro y neuronas, el psicoanálisis de deseo y lenguaje; la neuroética de materialismo biológico, el psicoanálisis de afecto primario que irrumpe desde el cuerpo; la neuroética de redes neurobiológicas, el psicoanálisis de dinamismos significantes del inconsciente; la neuroética de evolución de la especie, el psicoanálisis de historicidad y narración del sujeto; la neuroética de abolición y rechazo completos de la psicología cotidiana, el psicoanálisis de desenmascaramiento de la psicología popular; la neuroética de ética como adaptación evolutiva, el psicoanálisis de renuncia progresiva a la violencia inherente al hombre para dar paso al nacimiento de la institucionalidad y el derecho; la neuroética de perfeccionamiento de capacidades y creación de otras inéditas, el psicoanálisis de aclaramiento de la menesterosidad y vulnerabilidad del ser humano; la neuroética de un avance progresivo, 
libre y sin cortapisas, de la condición humana hacia metas insospechadas, el psicoanálisis de la superación de las ilusiones infantiles que arrastramos indefectiblemente producto de la historia; la neuroética de sobrepasar impedimentos y límites propios de ideologías científicas y sociales periclitadas para adentrarse en territorios inexplorados sin barreras de precaución, el psicoanálisis de utilizar la ciencia para crear, trabajar y gozar a partir de sublimaciones cada vez de un nivel superior, pero sin convertir a ésta en un nuevo ídolo.

4) La neuroética es una técnica de la dominación, del poder del saber que genera prácticas sobre el conocimiento de sí, sobre el individuo consigo mismo, sobre la subjetivación de la ética en el ser humano, sobre el sujeto en cuanto es poseedor y sobre todo ejecutante activo de la moral. Las ciencias naturales están planteando hipótesis contrastables que demuestran que somos cerebro ético, producto de la lucha por la supervivencia biológica, gracias a la reciprocidad originaria perdida en los siglos de la humanidad, pero que ha dejado huellas indelebles en nuestras neuronas. Ha llegado por fin el momento de pasar del "debe" moral al "es" cerebral, del mito de los juicios morales a los hechos éticos naturales. La conclusión preliminar, pero fuertemente avalada empíricamente, resulta clara: la conducta moral es innata y universal.

5) El psicoanálisis es una técnica de la veracidad, lo que busca es el acceso al discurso verdadero, al reconocimiento de sí por sí mismo. No es un conocimiento producto de los lugares comunes del habla cotidiana basados en la psicología popular, ni de la verdad objetiva que emite cualquiera sobre sí en una autodescripción, sino de un trabajo. Primero, es admitir la vergüenza y herida narcisista degradante que significa contemplarnos y con- fesarnos en nuestras falsedades y fingimientos que configuran y determinan nuestra interioridad. Luego de este trabajo de desocultación y desenmascaramiento, viene la lucha contra las fuerzas que se oponen, contra las resistencias, contra los autoengaños que surgen permanentemente, contra las seducciones que se intenta ejercer sobre sí y el terapeuta. La herramienta indispensable es la interpretación, la búsqueda del sentido veraz detrás de los sentidos defensivos, y el medio es la transferencia. Freud recurrió a la tragedia desde 1897, cuando comenzó a investigar lo ético en el ser humano, por ello, él es tan afín, aunque nunca lo mencionó, al coro de Agamenón de Esquilo: pathei-mathos, "la sabiduría (sinceridad) sólo se alcanza a través del sufrimiento" $(40,79,80)$.

6) Pero tanto la neuroética como el psicoanálisis parten de la ética como un fenómeno humano que ya está ahí; esto es, no se preguntan por aquello que es propiamente la moral, por la esencia de lo ético, ya que se lo presupone, se lo da por subentendido. Usando un ejemplo del psicoanálisis, aunque lo mismo es válido para la neuroética: una cosa es encontrar que la ligazón íntima con el maestro significa el cargar libidinalmente al objeto de manera homosexual, aunque de carácter reprimido, y otra muy diferente es creer que con ello se ha encontrado la respuesta final al problema de la autoridad de los valores, al fundamento del poder y del valor. Una cosa es solucionar el problema de la génesis, mecanismos y condiciones de lo ético, y otra básicamente distinta es el origen radical. A este origen primero se llama en el pensamiento filosófico "fundamento". Las ciencias, tanto la neuroética como el psicoanálisis de Freud, no pueden referirse al fundamento, por tanto, ni a su justificación, ni a su legitimación, ni a la prescripción.

\section{Referencias}

1. Safire W. Visions for a new field of "neuroethics". En: Marcus SJ, (ed.) Neuroethics: Mapping the field. New York: The Dana Press; 2002: 3-9.

2. Cortina A. Neuroética y neuropolitica. Sugerencias para la educación moral. Madrid: Tecnos;2011.

3. Figueroa G. Neuroética: reflexiones sobre los principios latentes de la moral en medicina. Rev Méd Chile 2012; 140: 1078-1084.

4. Figueroa G. Las ambiciones de la neuroética: fundar científicamente la moral. Acta bioethica 2013; 19(2): $259-268$.

5. Evers K. Neuroéthique. Quand la matière s'éveille. Paris: Jacob; 2009. 
6. Illes J, (ed.) Neuroethics. Defining the issues in theory, practice and policy. New York: Oxford University Press; 2006.

7. Freud S. Briefe an Wilhelm Fließ (1887-1904). Frankfurt: Fischer; 1986.

8. Nietzsche F. Götzen-Dämmerung. En: Nietzsche F. Werke in Drei Bänden. Zweiter Band. München: Carl Hanser; 1966 : 939-1032.

9. MacIntyre A. After virtue. London: Duckworth; 1985.

10. Vattimo G. Más allá del sujeto. Barcelona: Paidós; 1989

11. Hempel CG. Philosophie der Naturwissenschaften. München: Deutscher Taschenbuch-Verlag; 1974.

12. Rorty R. Philosophy and the mirror of nature. Princeton: Princeton University Press; 1979.

13. Bunge M. Epistemología. Barcelona: Ariel; 1985.

14. Kandel ER. A new intellectual framework for psychiatry. Am J Psychiatry 1998; 155: 457-469.

15. Kendler KS. Toward a philosophical structure for psychiatry. Am J Psychiatry 2005; 162: 433-440.

16. Libet B. Unconscious cerebral initiative and the role of conscious will in voluntary action. Behav Brain Sci 1985; 8: 529-566.

17. Libet B. Do we have free will? J Conscious St 1999; 6: 45-51.

18. Haggard P, Eimer M. On the relation between brain potentials and the awareness of voluntary movements. Exp Brain Res 1999; 126: 128-133.

19. Haidt J, Bjorklund E. Social intuitionists answer six questions about moral psychology. En: Sinnott-Amstrong W, (comp.) Moral psychology. Volume 2. Cambridge: The MIT press; 2008: 181-217.

20. Freud S. Trauer und Melancholie. En: Freud S. Gesammelte Werke X. Frankfurt: Fischer; 1916: 427-446

21. Freud S. Die Traumdeutung. En: Freud S. Gesammelte Werke II/III; 1900: 1-642.

22. Freud S. Zur Psychopathologie des Alltagslebens. En: Freud S. Gesammelte Werke IV. Frankfurt: Fischer; 1901.

23. Freud S. Das Unbehagen in der Kultur. En: Freud S. Gesammelte Werke XIV. Frankfurt: Fischer; 1930: 419-506.

24. Gazzaniga MS, Steven MS. Free will in the $21^{\text {st }}$ century: a discussion of neuroscience and the law. En: Gardland B (ed.) Neuroscience and the law. New York: Dana Press; 2004.

25. Morse SJ. New neuroscience, old problems. En: Garland B (ed.) Neuroscience and the law. Dana Foundation; 2004: 157-198.

26. Ryle G. The concept of mind. London: Penguin; 1990.

27. Freud S. Die Verbrecher aus Schuldbewubtsein. Freud S. Gesammelte Werke X. Frankfurt: Fischer; 1915: 389-391.

28. Haidt J. The emotional dog and its rational tail: a social intuitionist approach to moral judgement. Psychol Review 2001; 108: 814-834.

29. Kant I. Kritik der reinen Vernunft. Erster Teil. Werke. Band 3. Darmstadt: Wissenschaftliche Buchgesellschaft; 1968.

30. Freud S. Der Mann Moses und die monotheistische Religion. Gesammelte Werke XVI. Frankfurt: S. Fischer; 1939: 101-247.

31. Crick F. The atonishing hypothesis: The scientific search for the soul. New York: Simon \& Schuster; 1994.

32. Gazzaniga MS. The ethical brain. New York: Dana Press; 2005.

33. Gazzaniga MS. Who's in charge. New York: Ecco Books; 2011.

34. Roskies AL. Neuroethics for the new millennium. Neuron 2002; 35: 21-23.

35. Dennet D. Elbow room: the varieties of free will worth wanting. Cambridge: Bradford Bokks/ MIT Press; 1984.

36. Freud S. Studien über Hysterie. Gesammelte Werke I. Frankfurt: S. Fischer; 1895: 75-311.

37. Freud S. Das Ich und das Es. Gesammelte Werke XIII. Frankfurt: S. Fischer; 1923: 235-289.

38. Rorty R. Freud and moral reflection. En: Rorty R. Essays on Heidegger and others. Philosophical papers II. Cambridge: Cambridge University Press; 1991: 201-228.

39. Figueroa G. La bioética en el diván. ¿Puede Freud ayudarnos en los dilemas de la ética médica? Rev Méd Chile 2004; 132: 1550-1556.

40. Sófocles. Edipo Rey. En Sófocles. Tragedias. Madrid: Gredos; 1981: 301-367.

41. Illes J, Bird SJ. A modern context for ethics in neuroscience. Trends Neuroscien 2006; 6: 511-517.

42. Freud S. Preisausschreibung. Int Z Psychoanal 1922; 8: 527.

43. Decker HS. Freud in Germany: Revolution and reaction in science, 1893-1907. New York: International Universities Press; 1977.

44. Edelson M. Psychoanalysis. A theory in crisis. Chicago: University of Chicago Press; 1988. 
La ciencia irrumpe en la ética médica: neuroética y psicoanálisis de Freud - Gustavo Figueroa Cave

45. Holt RR. Freud reappraised. A fresh look at psychoanalytic theory. New York: The Guilford Press; 1989.

46. Crews F. Unauthorized Freud. Doubters confront a legend. New York: Viking; 1998.

47. Frosh S. For and against psychoanalysis. $2^{\text {nd }}$ edition. New York: Routledge; 2006.

48. Jacobsen K. Freud's Foes: Psychoanalysis, Science, and Resistance. Maryland: Rowland \& Littlefield; 2009.

49. Webster R. Why Freud was wrong? Sin, science and psychoanalys. New York: HarperCollins/Basic Books; 1996.

50. Eschenröder CT. Hier irrte Freud. Zur Kritik der psychoanalytischen. Theorie und Praxis. München: Piper; 1989.

51. Kandel ER. Biology and the future of psychoanalysis: a new intellectual framework for psychiatry revisited. Am J Psychiatry 1999; 156: 505-524.

52. Popper KL. Logik der Forschung. 11. Auflage. Tübingen: Mohr Siebeck; 2005.

53. Brooks P, Woloch A, (eds.) Whose Freud? The place of psychoanalysis in contemporary culture. New York: Yale University Press; 2000.

54. Rieff P. Freud. The mind of the moralist. $2^{\text {nd }}$ edition. New York: Viking Press; 1964.

55. Ricoeur P. De l'interpretation: Essai sur Freud. Paris: Editions du Seuil; 1965.

56. Ricoeur P. Écrits et conferences I. Autour de la psychoanalyse. Paris: Editions du Seuil; 2008.

57. Ricoeur P. The question of proof in Freud's psychoanalytic writings. Amer Psychoanal Ass 1977; 25: 835-871.

58. Ricoeur P. Le conflict des interpretations. Essais d'hermenéutique I. Paris: Editions du Seuil; 1969.

59. Figueroa G. ¿Qué es la neuroética? Boletín de la Academia Chilena de Medicina 2013; L: 89-100.

60. Wilson JQ. The moral sense. New York: Free Press; 1993.

61. Hauser MD. Moral minds: How nature designed our universal sense of right and wrong. New York: Abacus; 2008.

62. Unger P. Living high and letting die: Our illusion of inocence. New York: Oxford University Press; 1996.

63. Kant I. Kritik der praktischen Vernunft. Werke. Band 6. Darmstadt: Wissenschaftliche Buchgesellschaft; 1968: 105302.

64. Hamilton WD. The genetical evolution of social behaviour. J Theo Biology 1964; 7: 1-52.

65. Dawkins R. The selfish gene. New York: Oxford University Press; 1976.

66. Freud S. Zur Dynamik der Übertragung. Gesammelte Werke VIII. Frankfurt: S. Fischer; 1912: 363-372.

67. Austin JL. How to do things with words. New York: Oxford University Press; 1962.

68. Ricoeur P. Soi-même comme un autre. Paris: Editions du Seuil; 1990.

69. Freud S. Vorlesungen zur Einführung in die Psychoanalyse. Gesammelte Werke XI. Frankfurt: S. Fischer; 1917.

70. Freud S. Neue Folge der Vorlesungen zur Einführung in die Psychoanalyse. Gesammelte Werke XV. Frankfurt: S. Fischer; 1933.

71. Freud S. Totem und Tabu. Einige Übereinstimmungen im Seelenleben der Wilden und der Neurotiker. Gesammelte Werke IX. Frankfurt: S. Fischer; 1912/1913.

72. Gay P. Freud. A life for our time. New York: WW Norton \& Company; 1988.

73. Borch-Jacobsen M, Cottraux J, Pleux D, Van Rillaer J. Le livre noir de la psychanalyse. Vivre, penser et aller mieux sans Freud. Paris: Les Arènes; 2005.

74. Freud S. Erinnern, Wiederholen und Durcharbeite. Gesammelte Werke X. Frankfurt: S. Fischer; 1914: 125-136.

75. Figueroa G. Bioética de la muerte de Sigmund Freud ¿Eutanasia o apropiación? Rev Med Chile 2011; 139: 511-516.

76. Freud S. Die endliche und die Unendliche Analyse. Gesammelte Werke XVI. Frankfurt: S. Fischer; 1937: 57-100.

77. Heidegger M. Die Zeit des Weltbildes. En: Heidegger M. Holzwege. Frankfurt: Klosterman; 1963: 69-103.

78. Blass RB, Carmeli Z. The case against neuropsychoanalysis. Int J Psychoanal 2007; 88: 19-40.

79. Rudnytsky PL. Freud and Oedipus. New York: Columbia University Press; 1987.

80. Alford CF. The psychoanalytic theory of greek tragedy. New Haven and London: Yale University Press; 1992.

Recibido: 16 de febrero de 2015

Aceptado: 18 de marzo de 2015 